\title{
Working
}

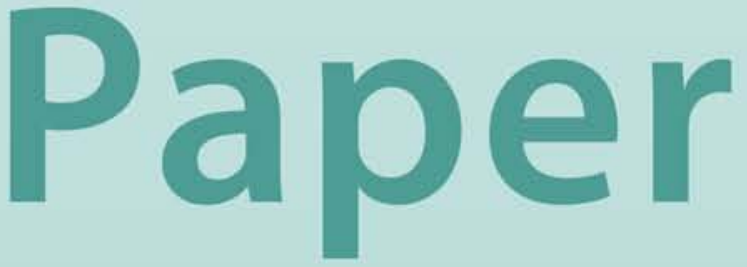


A Cross-Country Nonparametric Analysis of Bahrain’s Banking System

David Grigorian and Vlad Manole 


\title{
IMF Working Paper
}

Middle East and Central Asia Department

\section{A Cross-Country Nonparametric Analysis of Bahrain’s Banking System}

\author{
Prepared by David Grigorian and Vlad Manole ${ }^{1}$ \\ Authorized for distribution by Saade Chami
}

June 2005

\begin{abstract}

\section{This Working Paper should not be reported as representing the views of the IMF.} The views expressed in this Working Paper are those of the author(s) and do not necessarily represent those of the IMF or IMF policy. Working Papers describe research in progress by the author(s) and are published to elicit comments and to further debate.
\end{abstract}

Bahrain's financial sector development strategy succeeded in building a leading regional banking center, which has become one of the main engines of growth and sources of employment. Although the simulations conducted in the paper suggest that the banking sector in Bahrain continues to occupy a front-runner position among those in a sample of member countries of the Gulf Cooperation Council, they also reveal that: (i) as expected, banks in Bahrain still lag behind their Singaporean counterparts, and (ii) there is strong competition from other countries in the region. The paper also finds that in terms of scale efficiency, the banks in Bahrain operate at the same level as banks in Singapore and their closest competitors in Qatar and the United Arab Emirates. The results appear to be robust with respect to changes in the sample size and model specifications.

JEL Classification Numbers: C14, G21

Keywords: Data Envelopment Analysis, banking efficiency, Bahrain

Author(s) E-Mail Address:Dgrigorian@imf.org, Vmanole@worldbank.org

\footnotetext{
${ }^{1}$ Vlad Manole is at the Development Research Group of the World Bank.
} 


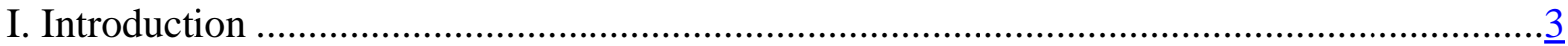

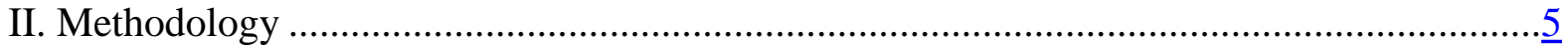

III. Results of Efficiency Analysis .......................................................................... $\underline{8}$

A. Baseline Specification.........................................................................

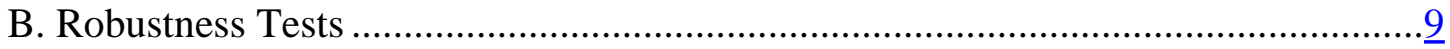

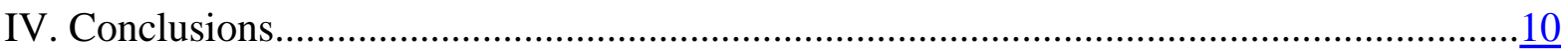

Tables

1. Number of Sample Banks by Countries, 1997-2003 …...............................................14

2. Number of Efficient Sample Banks by Country and Year ............................................15

3. Bahrain: Distribution of Efficiency Indexes by Types of Banks .......................................15

Figures

1. Conventional Indicators of Bank Performance, 1997-2002 ….......................................11

2. Cross-Country Comparisons of Efficiency Indexes, 1997-2003 ….................................12

3. A Robustness Test: Two-Input-Two-Output Case .....................................................13

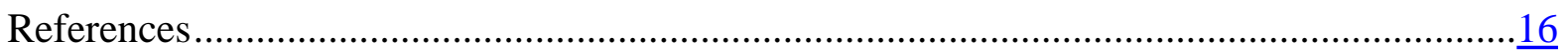




\section{INTRODUCTION}

The banking sector in Bahrain has grown rapidly in recent years, becoming one of the main engines of growth and sources of employment. This expansion was facilitated by rapid regional growth and the need to intermediate the substantial regional oil-related capital flows. The degree of intermediation is relatively high, with total commercial bank assets being in excess of 120 percent of GDP. ${ }^{2}$ Bahrain's legal and regulatory framework follows best international practice, contributing to the country's growing role as a financial center for the region. In 2002, the Bahrain Monetary Agency (BMA) consolidated the supervision and regulation of the financial sector (including banking, insurance, and capital markets) under one umbrella. Progress has been made in further increasing competition in the sector.

The development of the financial sector in Bahrain was marked by a gradual process that benefited from the region's financial needs following the civil war in Lebanon in the mid1970s. Since then, the Bahraini authorities took advantage of the large flow of funds due to the oil booms and opened the domestic financial market for major international players. Bahrain's location enables same-day financial transactions in the region and allows interactions with both eastern and western financial centers during business hours. Bahrain also offered many other benefits to financial institutions: a well-developed telecommunications infrastructure; market openness; easy access to Gulf Cooperation Council (GCC) markets and other countries in the region; a tax-free environment; no exchange restrictions; a well-trained labor force; high standards of living; stable exchange rate; and a solid regulatory environment. Against this background, a framework was established with a vision for Bahrain to become a regional financial-particularly offshorecenter. While the focus of the sector has shifted over the years away from offshore banking, the status of Bahrain as a financial center has strengthened.

While Bahrain's financial sector development strategy succeeded in building a leading regional banking center, there have been constant challenges on the way. External shockssuch as the uncertainties related to international oil markets, regional instability, and volatility in the international financial markets - have tested Bahrain's financial sector. Competition from other GCC countries has put pressure on the Bahraini financial industry to develop new products and instruments. Finally, difficulties related to the inability to broaden capital market activities beyond the banking sector, or expand the market beyond the region, raised concerns over the future of Bahrain as a financial center. ${ }^{3}$

\footnotetext{
${ }^{2}$ Although the size of the offshore banking sector is an impressive 24 times of Bahrain's GDP, the offshore banking units (OBUs) do not participate in domestic economic activities outside of providing very limited co-financing for large public-sector-led infrastructure projects.

${ }^{3}$ More recently, in light of Dubai's steps to encourage offshore banking as well as international pressures on the offshore banking business, Bahrain targeted Islamic finance as a source of growth in the financial sector. The strategy involves creating an efficient capital market with Islamic financial instruments operating in accordance with Shariah.
} 
Bahrain's financial sector offers a wide range of instruments and products. These include treasury bills and government development bonds, the Eurobond, government Islamic bonds, certificates of deposits, mutual funds, syndicated loans, foreign currency, commodities and financial futures, asset management, and precious metals. All commercial banks, OBUs, and investment banks are free to deal with each other, and with banks in other centers, in both Bahraini dinar and foreign currency.

The banking sector in Bahrain performed well in recent years. The commercial banks generated \$172 million in profits (with Islamic banks doubling their returns compared to 2002) and added double-digit returns to shareholders’ equity. All three largest OBUs incorporated in Bahrain saw their profits surge, and the sector as a whole more than tripled its annual earnings between 2002 and 2003. Despite this strong performance and the advanced regional status of the banking system, however, data reveal signs of high overhead costs and problems with the quality of loan portfolio, both contributing to high lending margins. (Table 1 depicts some conventional indicators of bank performance for a sizable population of Bahraini banks along with those from comparator country financial institutions). Although a large share of nonperforming loans is said to be carried over from the past (and was made to agents outside of Bahrain), the flow of new loans still appears to be vulnerable to collateral-related imperfections and excessive consumer lending.

The motivation behind the paper is straightforward: it attempts to assess the performance of the banking sector in Bahrain through a comparison with banks in the region and Singapore, a major Asian financial center. Such an assessment of efficiency and competitiveness (within regional and international contexts) can be important for a future reform agenda in Bahrain.

This paper looks beyond the conventional measures of performance of banks. In doing so, it compares the efficiency indicators of banks in Bahrain with that of their counterparts in Kuwait, Qatar, the United Arab Emirates, and Singapore, obtained by using a nonparametric estimation method called Data Envelopment Analysis (DEA). The DEA is a linear programming technique that constructs an efficiency frontier based on best performing banks, which is then used to assess the relative performance of other banks. One of the main advantages of this methodology is that it does not impose any functional forms and/or assumptions on the structure of the banks' objective function or the error term. As a result, it allows one to model other functions performed by the banks - apart from production of loans - such as liquidity and services provision. By treating every bank as a single decisionmaking entity, the paper defines a set of inputs and outputs and uses the most recent data to arrive at overall efficiency indexes for the sample banks. It then decomposes these indexes between purely technical and scale-related, thus offering additional insights with policy relevance.

The data used in the paper is obtained through BankScope database, and in the case of Bahrain, also contains updates and additions from the BMA. 


\section{Methodology}

During the past few decades, banking sectors around the world experienced profound regulatory and technological changes. Advanced applications in computer and communications technology, together with the introduction of new financial instruments, have significantly modified the technology of bank production and efficiency. This subsequently altered the way economists look at the functions performed by the banks and measure their efficiency. One of the methods used in the literature to evaluate productivity and performance of banks is the Data Envelopment Analysis, a nonparametric method that allows one to account for a wide range of functions performed by banks. This method compares relative performance of decision-making units (DMU) —in this case, banks_-by building a frontier comprised of the most efficient DMUs and focusing on how close other DMUs are to this frontier.

This was first proposed by Farrell (1957), who suggested constructing the frontier as a piecewise linear combination of the most efficient units. He also defined the most efficient DMUs to be those for which no other DMU or a linear combination of DMUs has as much or more of every output (given a fixed amount of inputs, for an output-oriented model) or as little or less of every input (given a fixed amount of outputs, for an input-oriented model). The efficiency frontier formed by connecting these best practice observations would yield a convex production possibility set. The DMUs falling inside the frontier are termed inefficient, and their performance would be measured vis-à-vis the frontier DMUs. Thus this method provides a measure of relative efficiency. In practice, this was first implemented by Charnes, Cooper, and Rhodes (1978), who used a linear-programming method to identify the efficient DMUs and coined the term Data Envelopment Analysis (DEA). ${ }^{4}$ The DEA has since been used extensively in studies of the banking industry in developed and developing market economies, for individual countries as well as inter-country comparisons. ${ }^{5}$

To arrive at basic specification of a linear-programming model underlying the DEA, we assume that there are $K$ inputs and $M$ outputs for every DMU. For the $i^{\text {th }}$ DMU the inputs and outputs are represented by vectors $x_{i}$ and $y_{i}$, respectively. For each DMU the method aims to obtain a measure of the ratio of all outputs over all inputs, such as $u_{i}^{\prime} y_{i} / v_{i}^{\prime} x_{i}$, where $u_{i}$ and $v_{i}$ are vectors of weights. To select the optimal weights, the following linear-programming problem is typically proposed:

\footnotetext{
${ }^{4}$ Their method is based on the assumption that the production units have constant returns to scale. Banker, Charnes, and Cooper (1984) later relaxed the assumption and proposed a model with units of production with variable returns to scale. Theoretical extensions of these methods and empirical applications are discussed in Seiford (1996) and Cooper, Seiford, and Tone (2000).

${ }^{5}$ See Berger and Humphrey (1997) for a detailed survey.
} 


$$
\begin{aligned}
\max _{u_{i k}, v_{i m}} & \frac{u_{i}{ }^{\prime} y_{i}}{v_{i}{ }^{\prime} x_{i}} \\
& \text { s.t. } \frac{u_{i}{ }^{\prime} y_{j}}{v_{i}{ }^{\prime} x_{j}} \leq 1 \\
& u_{i k}, v_{i m} \geq 0 \\
& i, j=1,2, \ldots N \\
& k=1,2, \ldots K \\
& m=1,2, \ldots M
\end{aligned}
$$

A problem with this formulation is that it has an infinite number of solutions. This can be avoided by introducing a constraint $v_{i}^{\prime} x_{i}=1$, and obtaining the multiplier form of the linear programming problem:

$$
\begin{aligned}
\max _{\mu_{i k}, \sigma_{i m}} & \mu_{i}{ }^{\prime} y_{i} \\
& \text { s.t. } \sigma_{i}{ }^{\prime} x_{i}=1 \\
& \mu_{i}{ }^{\prime} y_{j}-\sigma_{i}{ }^{\prime} x_{j} \leq 0 \\
& \mu_{i k}, \sigma_{i m} \geq 0 \\
& i, j=1,2, \ldots N \\
& k=1,2, \ldots K \\
& m=1,2, \ldots M
\end{aligned}
$$

where vectors $u_{i}$ and $v_{i}$ are replaced with $\mu_{i}$ and $\sigma_{i}$. Using the duality property of this linear programming problem, Charnes, Cooper, and Rhodes (1978) derive an equivalent envelopment form as:

$$
\begin{gathered}
\min _{\theta, \lambda} \theta_{i} \\
\text { s.t. }-y_{i}+Y \lambda_{i} \geq 0 \\
\theta_{i} x_{i}-X \lambda_{i} \geq 0 \\
\lambda_{\text {in }} \geq 0
\end{gathered}
$$

where $\lambda$ is an $(N \times 1)$ vector; and $\theta, \in[0.1]$ a scalar, is the efficiency score for the $i^{\text {th }}$ DMU. ${ }^{6}$ Essentially, $\theta_{i}$ is an indicator of how close a bank is to the efficiency frontier, with $\theta_{i}<1$

${ }^{6} X=\left[x_{1}, \ldots, x_{N}\right]$ is a $(K \times N)$ input matrix with columns $x_{i}$ and $Y=\left[y_{1}, \ldots, y_{N}\right]$ is an $(M \times N)$ output matrix with columns $y_{i}$. 
implying that the bank is inside the frontier (i.e., it is an inefficient bank), while $\theta_{i}=1$ implying that the bank is on the frontier (i.e., it is an efficient bank). Due to a fewer number of constraints, the formulation presented in equation 3 is typically used for computations.

The efficiency indexes calculated in such a way are termed overall technical efficiency (OTE) indexes. These can subsequently be decomposed into pure technical efficiency (PTE) and scale efficiency (SE) indexes, to help identify the source of inefficiency of each DMU in the sample. Skipping the details of the formulation, this relationship could be presented as:

$$
O T E_{i}=P T E_{i} \cdot S E_{i}
$$

To conceptualize this, note that the PTE index is calculated relative to a frontier characterized by variable returns to scale (i.e., either increasing, decreasing, or constant), while OTE is calculated relative to a frontier characterized by only constant returns to scale. Consequently, the $S E$ index captures the scale efficiency (i.e., due to increasing or decreasing returns to scale), while the PTE index captures nonscale and nonscope inefficiencies. ${ }^{7}$

Following the recent literature and bearing in mind the functions performed by commercial banks, ${ }^{8}$ three inputs to the banking "production process" are selected for the analysis: (i) personnel expenditures, to proxy for labor input, (ii) fixed assets, to proxy for premises, branch network, and equipment, and (iii) interest expenditures, to proxy for the amount of leveraged funds used in the process of intermediation. Next, we specify the following three outputs, which the above inputs are used to produce: (i) revenues, defined as the sum of interest and non-interest income; (ii) net loans, defined as loans net of loan loss provisions; and (iii) liquid assets, defined as the sum of cash and treasure bill holdings as well as balances with monetary authorities. Holding the outputs and two other inputs constant, the lesser amount of the third input used in the "production" would imply higher efficiency. Even though profit maximization is not implicitly modeled in equations 1-3, from the way the inputs and outputs are selected, one could think of the bank's objective as conditional or constrained profit maximization. Here the banks can be thought of as maximizing their revenues subject to a fixed level of costs and other outputs. For a given level of costs, maximizing revenues would be identical to maximizing profits.

\footnotetext{
${ }^{7}$ For functional forms as well as definitions of PTE, SE, and inefficiencies of scope, refer to Rezvanian and Mehdian (2002), who utilize the framework developed in Färe, Grosskopf, and Lovell (1985).

${ }^{8}$ There are five widely recognized functions performed by banks: profit maximization, risk management, service provision, intermediation, and utility provision (see, for instance, Bergendhal, 1998).
} 


\section{RESUlts OF EFFiciency ANALysis}

\section{A. Baseline Specification}

The analysis presented below is based on publicly available data compiled by BankScope. The set contains comprehensive financial data on a large number of banks from Bahrain, Kuwait, Qatar, the United Arab Emirates, and Singapore, the distribution of which by is shown in Table $1 .^{9}$ For each sample country, the number of available banks represents a vast majority of domestically incorporated commercial banks, both conventional and Islamic. Given the stage of development of the banking sectors in the sample countries, no major issues related to data quality and reporting standards are expected.

The results of DEA analysis by countries using the efficiency indexes estimated from equation 3, and their subsequent breakdown per equation 4, is presented in Figure 2. Table 2 reports the number of efficient banks in the sample by country and year. These results are largely consistent with one's expectations of relative performance of sample countries, and shed some light on potential sources of inefficiencies. A number of observations are worth noting in this regard.

First of all, as expected, at least when it comes to overall efficiency and pure technical efficiency indexes, Singaporean banks on average appear to be ahead of the curve. Although based on a somewhat different set of inputs and outputs, the results are consistent with those reported by Rezvanian and Mehdian (2002). For the period of 1991-1997, this study finds that the average values of OTE, PTE, and SE indexes are 0.74, 0.86, and 0.87, respectively, for a sample of ten Singaporean banks. Corresponding values based of our sample of 16 banks for $1997-2002$ are $0.70,0.88$, and $0.81 .^{10}$

Second, Bahrain appears to be ahead of the GCC sub-group, although there seems to be a tight competition from the United Arab Emirates and Qatar, as hypothesized above. Based on average overall indexes for 1997-2003, banks in Bahrain could be 43 percent more cost effective (i.e., use less inputs to produce the same amount of output, as their most efficient counterparts). That number for (a shorter period of) 1997-2002 for the United Arab Emirates and Qatar are 47 and 46 percent, respectively.

\footnotetext{
${ }^{9}$ As indicated earlier, the set contains 2003 data for four Bahraini banks provided by the BMA.
}

${ }^{10}$ An important caveat is in order here. Comparison of the results across these studies should be made with caution given the presence of non-Singaporean banks in our sample. However, the existence of GCC banks in the sample is relevant only to the extent that they are on the efficiency frontier (see Table 2). If all of them were located inside the frontier, they would not have changed the DEA outcome for Singaporean banks, making the comparison across studies more meaningful. 
Third, relative performance of sample banks by countries is not uniform across the efficiency measures (panels 2 and 3 of Figure 2). Even though banks in GCC countries appear to lag behind their Singaporean counterparts in terms of overall efficiency, the results for the United Arab Emirates, Bahrain, and Qatar appear to be at least as strong if measured by the SE index. Hence, the U.A.E. banks produce an average SE index of 0.87 for 1997-2002, while those in Singapore generate an average index of 0.81. The averages for Bahrain, Qatar, and Kuwait are equal to $0.83,0.84$, and 0.68 , respectively.

Fourth, in terms of absolute performance, the inefficiencies seem to be largely caused by purely technical inefficiencies and to a lesser extent by scale inefficiencies (i.e., banks operating either on the increasing or decreasing returns to scale portion of their underlying production functions). The average SE index for the sample banks in Bahrain for 1997-2003 is 0.83 , while the PTE index is equal to 0.70 .

Fifth, at least when it comes to the PTE index, there is a trend improvement for all sample countries, reducing the main source of inefficiency. This is largely consistent with new across-the-board developments in the information technology area and of new banking instruments and products (since the trend holds for all countries in the region), but also possibly through country-specific policies and developments (such as larger marginal impacts of capital account and financial sector liberalization, since some countries, such as Qatar and the United Arab Emirates, register growth rates well in excess of those in Singapore).

Sixth, as indicated in Table 3, there appears to be no statistically significant difference between efficiency indicators for conventional and Islamic banks.

\section{B. Robustness Tests}

To check the robustness of the above results, a test on a sub-sample of Bahraini and Singaporean banks was performed. In addition to limiting the sample to only two countries, the number of inputs and outputs was reduced to two. These now include fixed assets and interest expenditures as inputs, and revenues and liquid assets as outputs.

The results plotted on Figure 3 provide a solid consistency check for the DEA results discussed earlier. The relative pattern between the average Singaporean and Bahraini banks is preserved, and so is the breakdown of the overall efficiency index between pure technical and scale efficiencies. However, the analysis also suggests that once loans are excluded as an output and personnel expenditures excluded as an input, the gap between efficiency indexes among the sample of Singaporean and Bahraini banks declines. Generally this could imply a combination of: (i) inefficiencies related to scope of operations/products (in this case, loans) or (ii) inefficiencies related to use of inputs (in this case, employment resources). Both of these could have policy implications for Bahrain as they are likely to be a result of: (i) relatively large share of nonperforming loans (and as a result low net loan amounts) as well 
as the relative unattractiveness of loans as products, or (ii) a combination of inefficient use of labor and high wages and benefits. ${ }^{11}$

\section{Conclusions}

The linear programming technique and the results presented above provide a useful framework for analyzing Bahrain's banking sector performance and its competitiveness in the regional context. Although the simulations suggest that Bahrain occupies a front-runner position among the sample GCC countries, they also reveal that: (i) as expected, banks in Bahrain still lag behind their Singaporean counterparts, and (ii) there is strong competition from other countries in the region. The paper also finds that in terms of scale efficiency, banks in Bahrain operate at the same level as banks in Singapore and their closest competitors in Qatar and the United Arab Emirates. The results appear to be robust with respect to changes in the sample size and model specifications.

Further analysis would be required to pinpoint the exact type of inefficiencies in the sector, by looking at, among other things, the product mix and scope inefficiencies present in the banking sector in Bahrain. It will also be useful from the policymakers' perspective to look at the underlying sources of differences in performance among banks across countries, such as macroeconomic and prudential environments, size and concentration of the sector, banks' ownership structure, and other institutional factors. ${ }^{12}$ Follow-up studies should focus on the differences across these categories among GCC countries, Bahrain’s main competitors. Sustaining regional competitiveness would require continuous streamlining of regulatory restrictions, entry and exit rules, and collateral-related bureaucratic practices to limit their potential detrimental effect on banking efficiency. Optimal architecture of the banking sector would also require regional and international integration to guarantee transfers of new skills and technology through competitive pressures and the search for more profits.

\footnotetext{
${ }^{11}$ Unfortunately, the available data do not allow us to differentiate between the price and the quantity of inputs used (in this case labor), thus limiting our inferences about the efficiency of their use only to the overall value.

${ }^{12}$ See Grigoran and Manole (2002) for an application of this approach in the case of banks from 17 East European transition countries.
} 
Figure 1. Conventional Indicators of Bank Performance, 1997-2002
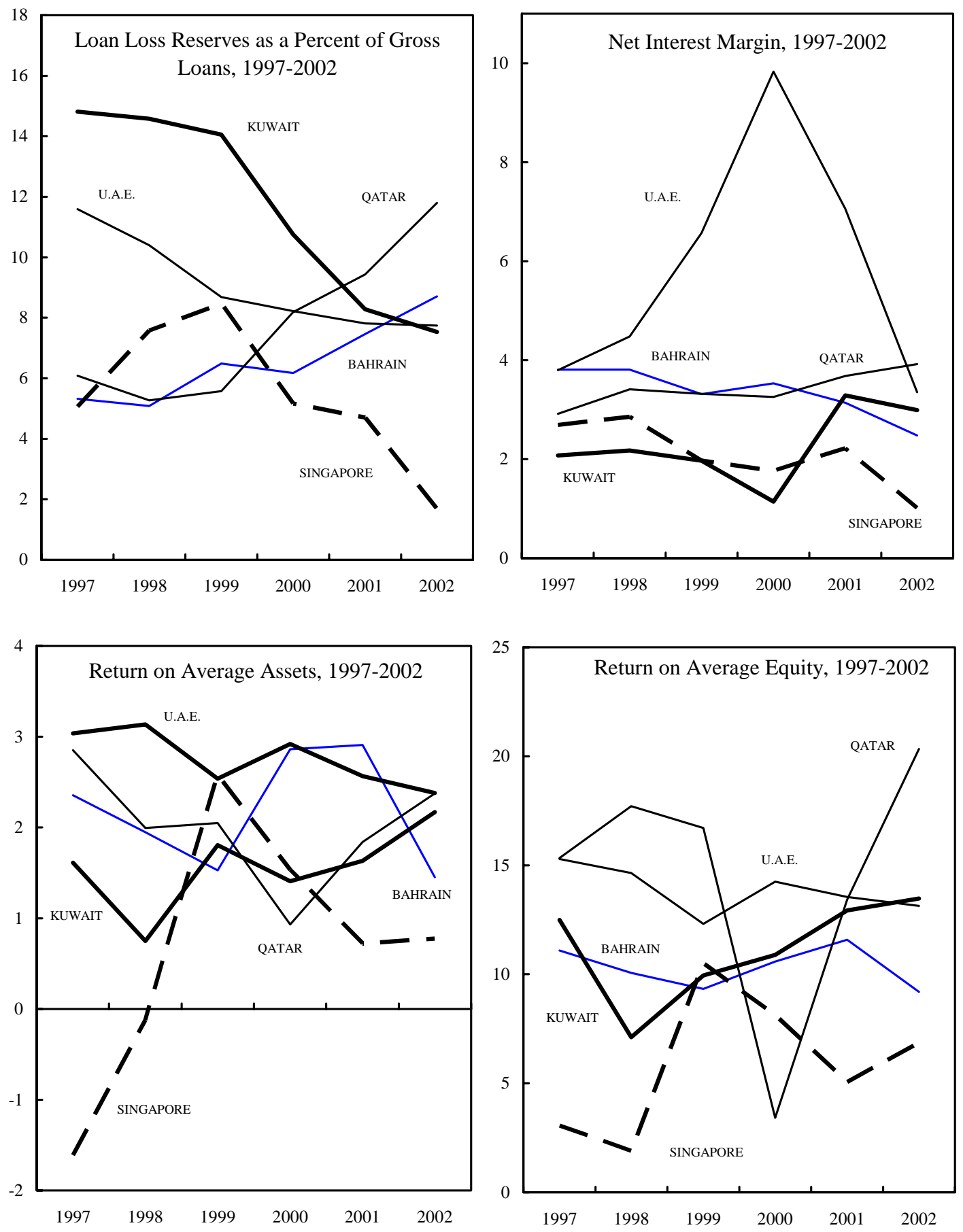

Source: BankScope 
Figure 2. Cross-Country Comparison of Efficiency Indexes, 1997-2003
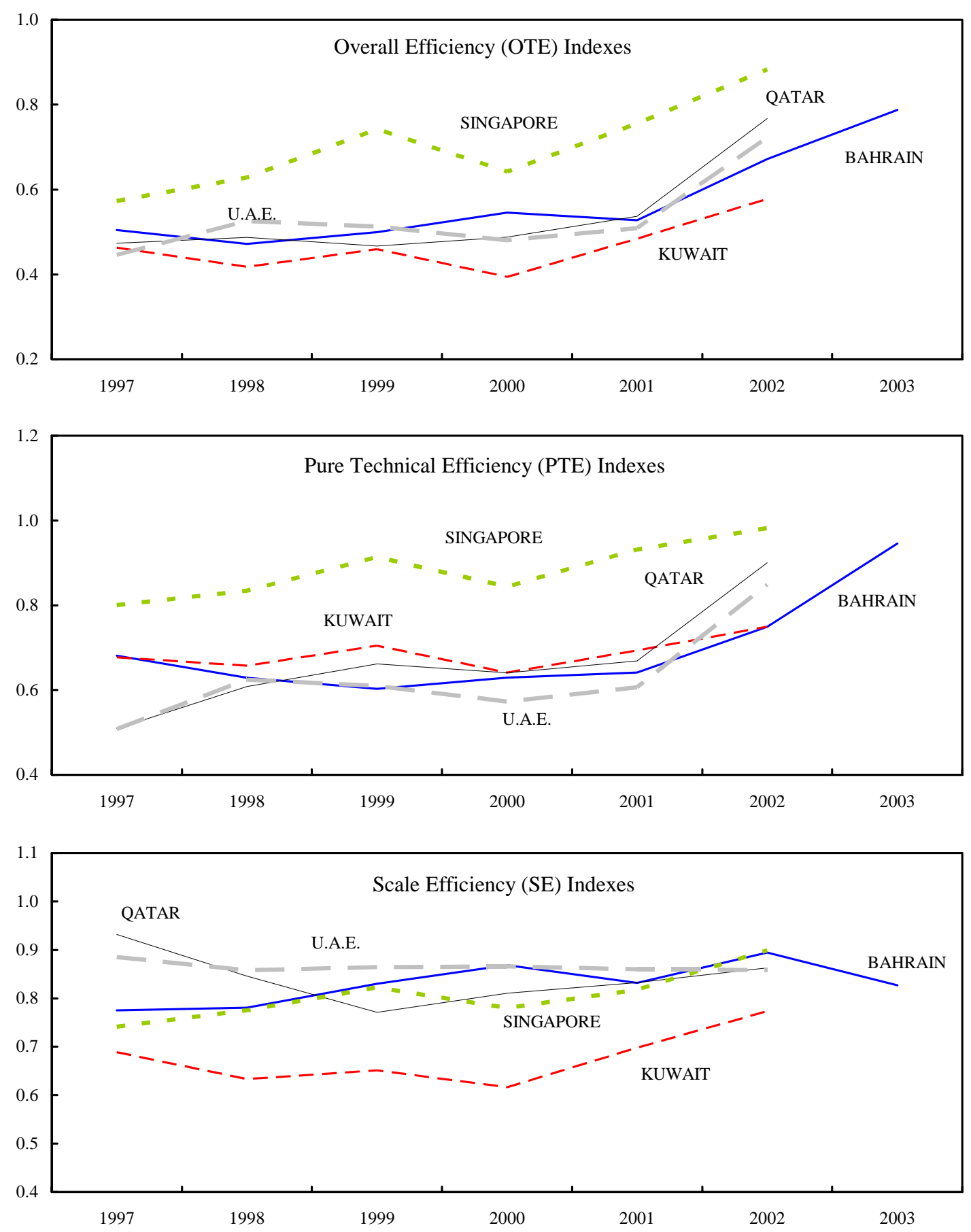

Source: Author's calculations. 
Figure 3. A Robustness Test: Two-Input-Two-Output Case

(Sample includes banks in Bahrain and Singapore, 1997-2002)
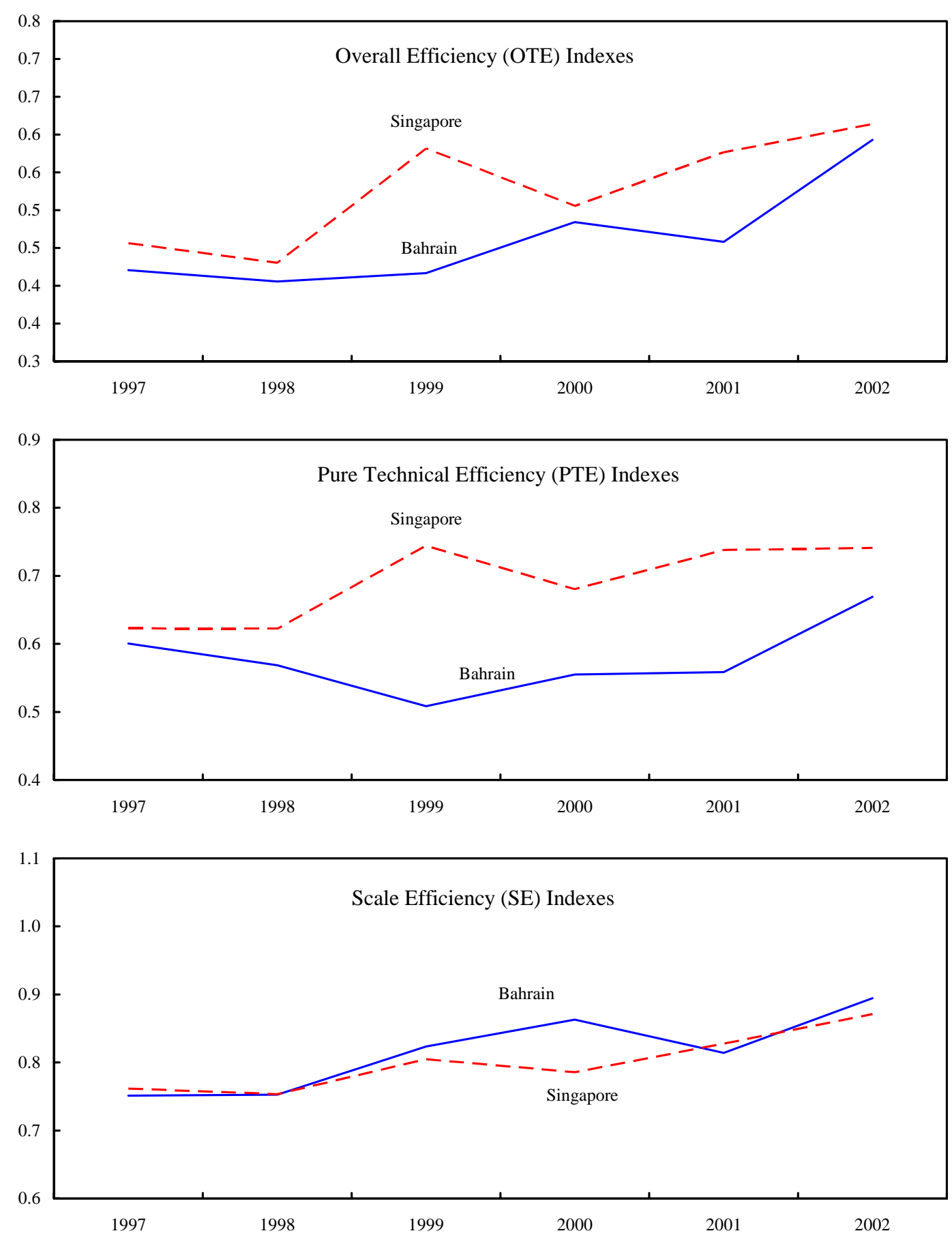

Source: Author's calculations. 
Table 1. Number of Sample Banks by Country, 1997-2003

\begin{tabular}{|c|c|c|}
\hline Country & Year & No. of Banks \\
\hline Bahrain & \multirow{6}{*}{1997} & 8 \\
\hline Kuwait & & 5 \\
\hline Qatar & & 2 \\
\hline Singapore & & 14 \\
\hline United Arab Emirates & & 3 \\
\hline Total & & 32 \\
\hline Bahrain & \multirow{6}{*}{1998} & 10 \\
\hline Kuwait & & 5 \\
\hline Qatar & & 4 \\
\hline Singapore & & 13 \\
\hline United Arab Emirates & & 10 \\
\hline Total & & 42 \\
\hline Bahrain & \multirow{6}{*}{1999} & 9 \\
\hline Kuwait & & 6 \\
\hline Qatar & & 5 \\
\hline Singapore & & 12 \\
\hline United Arab Emirates & & 10 \\
\hline Total & & 42 \\
\hline Bahrain & \multirow{6}{*}{2000} & 10 \\
\hline Kuwait & & 6 \\
\hline Qatar & & 5 \\
\hline Singapore & & 16 \\
\hline United Arab Emirates & & 12 \\
\hline Total & & 49 \\
\hline Bahrain & \multirow{6}{*}{2001} & 8 \\
\hline Kuwait & & 6 \\
\hline Qatar & & 7 \\
\hline Singapore & & 12 \\
\hline United Arab Emirates & & 12 \\
\hline Total & & 45 \\
\hline Bahrain & \multirow{6}{*}{2002} & 6 \\
\hline Kuwait & & 6 \\
\hline Qatar & & 6 \\
\hline Singapore & & 8 \\
\hline United Arab Emirates & & 12 \\
\hline Total & & 38 \\
\hline Bahrain & 2003 & 4 \\
\hline Grand Total & & 252 \\
\hline
\end{tabular}


Table 2. Number of Efficient Sample Banks by Country and Year 1/

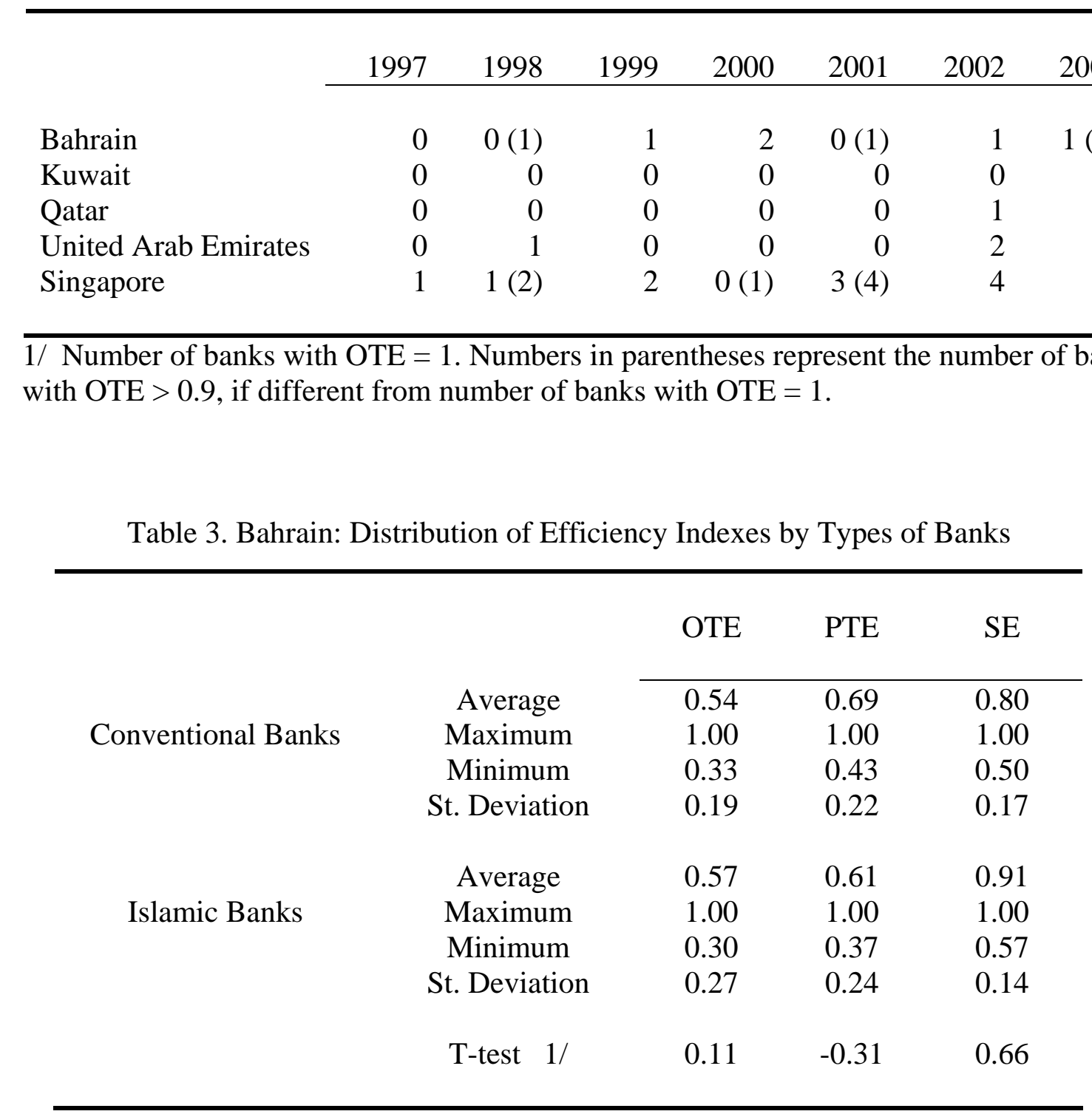

1/ Test for equal sample averages across conventional and Islamic banks. 


\section{References}

Banker, R.D., A. Charnes and W.W. Cooper, 1984. Some Models for Estimating Technical and Scale Inefficiencies in Data Envelopment Analysis. Management Science, 30, 1078-1092.

Bergendahl G., 1998. DEA and Benchmarks - An Application to Nordic Banks, Annals of Operations Research, Vol. 82, 233-249.

Berger A. N. and D. B. Humphrey, 1997. Efficiency of Financial Institutions: International Survey and Directions for Future Research. European Journal of Operational Research, Vol. 98, No. 2, 175-212.

Charnes A, W. W. Cooper, and E. Rhodes, 1978. Measuring the Efficiency of Decision Making Units. European Journal of Operations Research, No. 2, 429-44.

Cooper, W.W., L. M. Seiford and K. Tone, 2000. Data Envelopment Analysis. Kluwer Academic Publishers, Norwell, MA.

Färe, R., S. Grosskopf, and C.A. K. Lovell, 1985. The Measurement of Efficiency of Production, Kluwer Academic Publishing, Boston, MA.

Farrell, M. J., 1957. The Measurement of Profit Efficiency. Journal of the Royal Statistical Society, Series A, CXX, Part 3, 253-290.

Grigorian, D., and V. Manole, 2002. Determinants of Commercial Bank Performance in Transition: An Application of Data Envelopment Analysis, IMF Working Paper 02/146.

Rezvanian, R., and S. Mehdian, 2002. An Examination of Cost Structure and Production Performance of Commercial Banks in Singapore, Journal of Banking and Finance, Vol. 26, 79-98.

Seiford, L. M., 1996. Data Envelopment Analysis: The Evolution of the State of the Art (1978-1995). Journal of Productivity Analysis, Vol. 7, July 1996: 99-137. 